\title{
BREXIT, DIREITO CONTRATUAL EUROPEU E MERCOSUL: LIÇÕES PARA A INTEGRAÇÃO
}

\author{
BREXIT, EUROPEAN CONTRACT LAW AND THE MERCOSUL: LESSONS FOR INTEGRATION
}

\begin{abstract}
BREXIT, DERECHO CONTRACTUAL EUROPEO Y MERCOSUR: LECCIONES PARA LA INTEGRACIÓN
\end{abstract}

\section{Frederico E. Z. Glitz ${ }^{1}$}

Licença CC BY:

Artigo distribuído sob os termos Creative Commons, permite uso e distribuição irrestrita em qualquer meio desde que $o$ autor credite a fonte original.

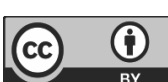

\begin{abstract}
Resumo: O presente artigo teve por objetivo a análise dos potenciais desdobramentos, no âmbito do Direito contratual, da retirada do Reino Unido do seio da União Europeia. Esta decisão, sob a qual ainda pesam inúmeras incertezas, trouxe questionamentos sobre o futuro da construção de um Direito Contratual europev e sobre as consequências normativas do desmonte de todo arcabouço normativo já construído. A aproximação, ainda que prospectiva, deste movimento permitiu a comparação da construção europeia com as perceptivas mercosulinas, evidenciando a distância da construção normativas dos dois projetos de integração. A análise exploratória e comparativa do BREXIT com a realidade do MERCOSUL, acompanhadas de metodologia indutiva, ajudou a concluir os desafios que precisam ser enfrentados por aqueles que pretendem a criação de um Direito contratual comunitário.
\end{abstract}

Palavras-chave: Direito contratual. Europeização. BREXIT. MERCOSUL.

1 Doutor em Direito das Relações Sociais pela Universidade Federal do Paraná (2011). Mestre em Direito das Relações Sociais pela Universidade Federal do Paraná (2005). Especialista em Direito dos Negócios Internacionais pela Universidade Federal de Santa Catarina (2003). Especialista em Direito Empresarial pelo Instituto de Ciências Sociais do Paraná (2002). Graduado em Direito pela Universidade Federal do Paraná (2000). Professor titular da UNOCHAPECÓ e da UNICURITIBA. Membro do Programa de Mestrado em Direito da UNOCHAPECÓ. Coordenador dos Cursos de Especialização em Direito Civil e Processo Civil e do curso de Especialização em Direito Contratual do UNICURITIBA. Membro do Conselho Editorial de vários periódicos especializados nacionais e internacionais. Vice-presidente da Comissão de Propriedade Intelectual da OAB/PR. Componente da lista de árbitros da Câmara de Arbitragem e Mediação da Federação das Indústrias do Paraná (CAMFIEP). 
Mercosul, demonstrating the distance in regulatory construction between the two integration products. This exploratory and comparative analysis of BREXIT with the reality of the MERCOSUL, accompanied by the inductive methodology, led to the conclusion that the challenges that need to be faced by those who aim to create a community contract Law.

Keywords: Contract law; Europeanization; BREXIT, MERCOSUL.

Resumen: Este artículo tiene como objetivo analizar las posibles consecuencias de la retirada del Reino Unido de la Unión Europea en el marco de lo Derecho Contractual. Esta decisión, en virtud del cual todavía pesan numerosas incertidumbres, trae preguntas sobre el futuro de la construcción de un Derecho contractual europeo y de las consecuencias normativas del desmantelamiento de todo el marco normativo ya construido. El enfoque, aunque prospectivo, de este movimiento permitió la comparación de la integración europea con la perspectiva mercosulinas, que muestra la distancia desde la construcción normativa de los dos proyectos de integración. El análisis exploratorio y comparativo de BREXIT con la realidad del MERCOSUR, con una metodología inductiva, ayudó llegar a la conclusión acerca de los desafíos que se deben enfrentar por aquellos que buscan la creación de un Derecho contractual comunitario.

Palabras clave: Derecho contractual. Europeización. BREXIT. MERCOSUR.

\section{INTRODUÇÃO}

No final de junho de 2016, o mundo foi surpreendido com a notícia de que o Reino Unido havia decidido, em referendo, retirar-se do bloco europeu. Tratavase do denominado "Brexit"2. O plebiscito havia sido uma promessa de campanha do então premiê britânico que, por sua vez, também não resistiu no cargo. A possibilidade de desmonte parcial da União europeia não era, contudo, inédita. Durante a crise econômica de 2012, muitos haviam aventado a possibilidade de a Grécia acabar se retirando do bloco europeu, caso não fosse possível atingir um acordo com seus credores europeus. Naquela oportunidade, o desmembramento foi superado.

Desta vez, entretanto, a União Europeia não só perderia um de seus membros mais antigos 3 , como uma das principais economias do Velho Mundo decidia tomar caminho próprio, distinto daquela bem-sucedida união econômica. Essa decisão, ainda, teria sido tomada pela recusa britânica em aceitar a política humanitária europeia de recepção de refugiados. Seria, portanto, mais um exemplo de uma crise gerando outra 4 .

2 Acrônimo resultante da junção dos termos "Britain" (Reino Unido) e "Exit" (saída).

3 A adesão do Reino Unido a então Comunidade Europeia se deu em $1^{\circ}$ de janeiro de 1973.

4 Os dados do referendo indicam que a decisão pelo Brexit foi majoritária na Inglaterra menos urbana. Por outro 
A possibilidade de um Estado membro se desligar da união econômica é institucionalizada e está prevista no art. 50 do Tratado de Lisboa ${ }^{5}$. O próprio framework europeu, portanto, prevê o mecanismo de sua desmobilização. Nesse sentido, o país interessado em se desvincular do bloco europeu precisaria notificar esta decisão ao Conselho Europeu, passando a União a negociar o formato da futura relação entre o bloco e o país retirante. O eventual acordo alcançado seria aprovado por maioria qualificada do Conselho, após a provação pelo parlamento europeu.

Embora ainda não se possam apontar quais serão todas as consequências jurídicas dessa decisão, sabe-se que haverá sensível influência não só para o Direito Europeu como para a atual construção de um Direito contratual europeu.

Este breve artigo pretende, a partir da desmobilização parcial do mais bemsucedido esforço de integração regional, entender as consequências mais amplas para o Direito Contratual e para o processo de construção de um Direito Europeu dos Contratos. Essa análise, portanto, também é feita sob a perspectiva brasileira e do Mercado Comum do Sul (MERCOSUL), em que os esforços de construção de um Direito comunitário ainda são muito resumidos. As perspectivas da experiência europeia podem servir não só de alerta, como também de precedente para futuras tentativas mercosulinas.

Este artigo apresenta parte da hipótese de que o Brexit ajuda a compreender as consequências da extinção parcial de um verdadeiro Direito Contratual comunitário. Parte-se, ainda, da premissa de que as consequências do BREXIT, em matéria de Direito Contratual, podem ajudar a formatar a futura e eventual criação de um Direito Contratual comunitário do MERCOSUL em sentido estrito.

Partindo dessas hipóteses, é possível afirmar que o problema enfrentado por este artigo é, justamente, a partir da experiência europeia, como um Direito contratual comunitário é formado e quais as dificuldades que podem surgir a partir de tentativa de sua extinção parcial por iniciativa de um Estado membro.

Para que se possam compreender, ainda que em perspectiva, as possíveis consequências do Brexit para o Direito Contratual europeu, o trabalho, em um

lado, países como a Escócia e a Irlanda do Norte foram majoritariamente pela permanência. Os dados estão disponíveis em: http://www.bbc.com/news/politics/eu_referendum/results. Acesso em: 03/10/2016.

5 Disponível em: http://www.lisbon-treaty.org/wcm/the-lisbon-treaty/treaty-on-european-union-and-comments/title-6final-provisions/137-article-50.html. Acesso em: 03/10/2016. 
primeiro momento do artigo, descreve-se o processo de criação deste mesmo Direito. Em seguida, trata-se das consequências normativas do Brexit para o Direito Contratual europeu. Por fim, no terceiro item, busca-se evidenciar as possíveis consequências do desmonte do processo de integração para o Direito Contratual em criação em uma realidade europeia como aquela do MERCOSUL.

Ainda que as perspectivas de ambos os processos de integração sejam distintas, esta abordagem, em grande parte indutiva, permitirá avaliar o grau de existência de um Direito Contratual do MERCOSUL, comparando-o, justamente, com a potencial crise que representaria a retirada de um Estado membro. Advertese, então, que o foco de análise será, exclusivamente, o Direito Contratual.

Para que se possa responder ao problema proposto, o artigo parte de pesquisa bibliográfica e normativa comparativa, valendo-se do método indutivo. Dada a escassez de trabalhos sobre o tema, o presente artigo é propositivo, ao mesmo tempo em que busca identificar na crise europeia dificuldades e soluções ainda não experimentadas no MERCOSUL. Eis o que se passa a fazer.

\section{A CONSTRUÇÃO DE UM DIREITO EUROPEU DOS CONTRATOS?}

Os séculos XX e XXI são, reconhecidamente, marcados pelas iniciativas de harmonização e uniformização normativa em matéria contratual. Este movimento é experimentado tanto em nível regional como mundial, aproveitando não só o Brasil, mas também o MERCOSUL e a União Europeia. Os exemplos mais bem-sucedidos destas tentativas podem ser encontrados tanto nos trabalhos de organismos interestatais (UNCITRAL ${ }^{6}$, por exemplo), como nos esforços de organismos privados (como o UNIDROIT ${ }^{7}$ ).

Além destas iniciativas formais de uniformização e harmonização, percebe-se o forte incentivo para a construção de fontes normativas privadas, especialmente pelo reconhecimento de figuras típicas de soft Law. Seria, em outros termos, a afirmação da existência de normas de origem variada, as quais descrevem situações fáticas e comportamentos esperados sem que lhe seja, no entanto, reconhecida a coercitividade típica de normas jurídicas formais.

6 Comissão das Nações Unidas para o Direito Comercial Internacional. Disponível em www.uncitral.org. Acesso em: 04/10/2016.

7 Instituto Internacional para a Unificação do Direito Privado. Disponível em www.unidroit.org. Acesso em: 04/10/2016. 
A grande relevância deste processo é, justamente, a flexibilização que estas outras fontes normativas imprimem às normas de conflito, dinamizando as fontes ${ }^{8}$. Este movimento, aliás, já é bem conhecido por alguns de seus exemplos: os Princípios dos Contratos Comerciais Internacionais e os Princípios Contratuais Europeus ${ }^{9}$ e os Princípios da Haia sobre a escolha do Direito aplicável aos contratos comerciais internacionais ${ }^{10}$.

Em matéria contratual, cada vez mais parece se evidenciar que a iniciativa meramente estatal não seria suficiente para a total normatização do Direito Contratual em nível internacional. Desta aparente complexidade é que resulta o reconhecimento e, em alguma medida, o empoderamento de outros atores internacionais e de outros modelos normativos que pudessem auxiliar na organização normativa do tráfego jurídico. Vários destes instrumentos, com o tempo, passaram a ser incorporados em âmbitos mais amplos que os regionais ou locais, sempre objetivando garantir algum nível de previsibilidade normativa às relações contratuais que, de outra forma, poderiam estar submetidas a vários distintos sistemas legislativos e perspectivas culturais nacionais ${ }^{11}$. Resta claro, também, que este fenômeno se justifica não apenas por questões culturais, mas pelo grande interesse na instrumentalização de operações econômicas, facilitando as trocas de bens, serviços e capitais ${ }^{12}$.

Assim, seja pela uniformidade ou harmonização, sistemas normativos compartilhariam soluções, mecanismos e conceitos que promoveriam a circulação mais eficiente de bens e serviços, diminuindo os custos de transação e incrementando o comércio internacional ${ }^{13}$, ao mesmo tempo em que buscariam evitar as dificuldades típicas do conflito de leis ${ }^{14}$.

$8 \quad$ BASSO, Maristela. Curso de Direito Internacional Privado. São Paulo: Atlas, 2009, p. 78-80.

9 GOODE, Roy; KRONKE, Herbert; MCKENDRICK, Ewan. Transnational commercial law: texts cases and materials. Oxford: Oxford press, 2007, p. 505.

10 Disponível em: https://www.hcch.net/pt/instruments/conventions/full-text/?cid=135. Acesso em: 18/01/2017.

11 AMISSAH, Ralph. The Autonomous Contract: Reflecting the borderless electronic-commercial environment in contracting. Disponivel em: http://www.jus.uio.no//m//the.autonomous.contract. 07.10.1997.amissah/doc.html. Acesso em: 1\%/10/2016.

12 ALPA, Guido. Les nouvelles frontières du droit des contrats. In: Revue internationale de droit comparé. v. 50, n. 4. out./dez. 1998, p. 1019.

13 CARBONARA, Emanuela; PARISI, Francesco. The Economics of Legal Harmonization. In: German Working Papers in Law and Economics, n. 1, 2006, p. 02-30.

14 MORENO RODRÍGUEZ, José Antonio. Temas de contratación internacional, inversiones y arbitraje. Asunción: 
Em uma perspectiva europeia, a harmonização contratual internacional é historicamente buscada por meio de três iniciativas: (i) a de criação de um Direito Europeu dos Contratos, (ii) o projeto de um Código Europeu dos Contratos e (iii) a redação de princípios uniformes do Direito Contratual Internacional ${ }^{15}$.

Todos estes empreendimentos se diferenciam na forma, na abrangência e nos objetivos: enquanto a criação de um Direito Europeu dos Contratos tem contornos obrigatórios típicos, formados de Diretivas e regulamentos; a discussão sobre um projeto de Código Europeu dos Contratos é de abordagem teórica, já a redação de princípios uniformes busca a codificação do Direito Contratual Internacional. Em termos de abrangência, as duas primeiras propostas são regionais (limitadas à Europa) e a última teria caráter internacional mais amplo. Por fim, o projeto de Código Europeu tem pretensões de formar a parte geral de um Código Civil, enquanto que a redação de princípios uniformes busca resolver questões práticas ${ }^{16}$.

Por outro lado, este processo de harmonização do Direito Contratual é, usualmente, influenciado por alguns outros fatores: (i) a revisão das codificações nacionais; (ii) a criação de codificações internacionais; (iii) a adoção de Convenções regionais cuja regência possa ser eleita pelas partes; (iv) a adoção de regras uniformes de origem privada; ( $v$ ) a adoção universal de procedimentos arbitrais para solucionar disputas comerciais; (vi) o ressurgimento da prática comercial costumeira e (vii) o restatement internacional ${ }^{17}$. A Europa, neste sentido, é bastante profícua em exemplos: (i) a recentíssima revisão do Código Civil francês ${ }^{18}$; (ii) os Princípios UNIDROIT relativos aos contratos comerciais internacionais (2010) ${ }^{19}$; (iii) a Convenção de Viena de 1980 sobre compra e venda internacional de Mercadorias (1980)20; os International Commercial Terms (Incoterms) coligidos pela Câmara Internacional do Comércio (CCI); o regimento arbitral da Câmara Arbitral da própria $\mathrm{CCI}$ que tanto influenciou a redação de outros, mundo afora; etc.

CEDEP, 2006, p. 65.

15 ALPA, Guido. Les nouvelles frontières du droit des contrats. In: Revue internationale de droit comparé. v. 50, n. 4. out./dez. 1998, p. 1022-1024.

16 ALPA, Guido. Les nouvelles frontières du droit des contrats. In: Revue internationale de droit comparé. v. 50, n. 4. out./dez. 1998, p. 1022-1024.

17 ROSSET, Arthur. UNIDROIT Principles and Harmonization of International Commercial Law: focus on Chapter Seven. Disponível em: www.unidroit.org/english/publications/review/articles/ 1997-3-rosett-e.pdf. Acesso em: 05/10/2016.

18 Disponível em: https://www.legifrance.gouv.fr/affichTexte.do;jsessionid=604A2DE2CD 769D2E0BF1467515AD50FD. tpdila10v_3?cidTexte=JORFTEXT000032004939\&categorieLien =id. Acesso em: 05/10/2016.

19 Disponível em: http://www.unidroit.org/english/principles/contracts/principles2010/ translations/blackletter2010portuguese.pdf. Acesso em: 05/10/2016.

20 Disponível em: www.uncitral.org/uncitral/en/uncitral_texts/sale_goods/1980CISG.html. Acesso em: 05/10/2016. 


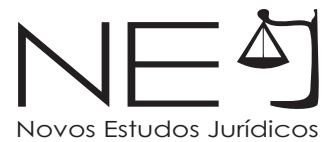

Em âmbito europeu, tais iniciativas acabariam fornecendo não só a possibilidade da mencionada harmonização ou uniformização, como poderiam servir de alternativa à dificuldade institucional de criação de um "Código Europeu dos Contratos". Lembre-se, sempre, que a União não pode intervir nas legislações nacionais na justificativa do Tratado constitutivo ${ }^{21}$, o que tornaria, no mínimo, questionável a edição de uma codificação contratual europeia. Este nível de dificuldades fez com que a Comissão europeia adotasse um plano de ação propondo uma estratégia mista (regulatória e não regulatória) para intervenção no Direito dos Contratos, com o objetivo de ampliar o debate sobre o tema ${ }^{22}$, o que acabou gerando uma série de iniciativas que buscavam identificar o "Common Frame of Reference", ou seja, o quadro jurídico comum que poderia vir a permitir a harmonização da matéria contratual em termos europeus.

Alguns destes estudos já vinham sendo realizados por iniciativa própria e independente da provocação europeia, dentre os quais devem ser destacados os trabalhos realizados pela UNIDROIT, a elaboração dos Princípios de Direito contratual europeu (PECL), os princípios coligidos pela Translex ${ }^{23}$, o Common Core Project e os trabalhos do grupo Acquis.

Os PECL se apresentam sob a forma de artigos acompanhados de comentários e notas de aplicação nacional. Foram elaborados pela chamada Comissão Lando, que teve por missão a análise comparada da legislação dos Estados membros da União europeia de modo a desenvolver os "Princípios" fundamentais do Direito Contratual Europeu, uma vez que suas disposições se referem apenas à parte geral do Direito dos contratos. Foram publicados em três partes e definitivamente completados em 200124. Seu âmbito de aplicação incluiria os contratos de consumo, mas, por outro lado, se limitariam às transações domésticas ${ }^{25}$. Esta, aliás, é sua principal distinção em relação aos Princípios UNIDROIT relativos

21 MORAIS, Fabíola. Aproximação do Direito Contratual dos Estados-membros da União Européia. Rio de Janeiro: Renovar, 2007, p. 23.

22 Communication from the Commission to the Council and the European Parliament on European contract law [COM(2001) 398 final - Official Journal C 255 of 13.9.2001]. Disponível em: http://eur-lex.europa.eu/legal-content/ EN/TXT/?uri=URISERV\%3AI33158. Acesso em: 25/10/2016.

23 Disponível em: www.trans-lex.org. Acesso em: 05/10/2016.

24 EUROPA. Comissão Lando. Principles of European Contract Law. Disponível em: www.jus.uio.no/Im/eu.contract. principles.parts.1.to.3.2002/toc.html. Acesso em: 05/10/2016.

25 PEREIRA, Teresa Silva. Proposta de reflexão sobre um Código Civil europeu. In: Revista da Ordem dos Advogados Portugueses, v. 2, nov. 2004. Disponível em: www.oa.pt/Conteudos/Artigos/detalhe_artigo.aspx?idc=31559\&idsc= 45841\&ida=47182. Acesso em: 05/10/2016. 
aos contratos comerciais internacionais $(\mathrm{PICC})^{26}$. Ole Lando, contudo, propõe sua adoção como modelo legislativo, fundamento para julgamentos e Direito de regência de contratos internacionais ${ }^{27}$, o que, de alguma forma, afronta o alegado objeto. O próprio autor, em outra oportunidade, já havia sustentado a necessidade da existência de um Código Contratual global, esboçando, mesmo, algumas de suas regras básicas a partir da comparação entre os PECL, os PICC e a CISG ${ }^{28}$.

De forma concomitante estavam sendo desenvolvidos os trabalhos para o Código Civil Europeu pela Study Group on a European Civil Code (SGECC) ${ }^{29}$, que utiliza os PECL como ponto de partida para seu projeto.

Destaque se dê, ainda, ao papel desempenhado pelo grupo Acquis ${ }^{30}$ no levantamento do Direito Contratual já existente no Direito Europeu (Diretivas, jurisprudência, etc.) de modo a identificar os princípios gerais que o regem e, eventualmente, motivando a reforma legislativa ${ }^{31}$. Também merece destaque a Academia de Pávia ${ }^{32}$ que, sob a coordenação do Prof. Giuseppe Gandolfi, tratou de elaborar proposta de código para o Direito Contratual Europeu ${ }^{33}$ argumentando não se tratar daquele modelo liberal de codificação, mas um código adequado aos tempos atuais, que deixasse espaço para as fontes complementares e integrativas ${ }^{34}$.

A Law Comission inglesa, a cargo de Harvey Mcgregor ${ }^{35}$, e o Common Core Project ${ }^{36}$ (Projeto de Trento) também são relevantes iniciativas. Este último, diferentemente dos demais projetos, não busca a harmonização ou a unificação do Direito Contratual Europeu, mas a construção de uma cultura comum ${ }^{37}$. Seu método de trabalho se

26 LANDO, Ole. Principles of European Contract Law and Unidroit Principles: Similarities, Differences and Perspectives. Disponível em: www.cisg.law.pace.edu/cisg/biblio/lando6.html. Acesso em: 05/10/2016; BONELL, Michael Joachim. The UNIDROIT Principles of International Commercial Contracts and the Principles of European Contract Law: Similar Rules for the Same Purposes? In: Uniform Law Review, 1996, p. 229-246.

27 LANDO, Ole. The Rules of European contract law. Disponível em: www.cisg.law.pace.edu/cisg/biblio/lando2.html. Acesso em: 05/10/2016.

28 LANDO, Ole. CISG and Its Followers: A Proposal to Adopt Some International Principles of Contract Law. In: American Journal of Comparative Law, v. 53, 2005, p. 379-401.

29 Disponível em: www.sgecc.net. Acesso em: 05/10/2016.

30 Disponível em: www.acquis-group.jura.uni-osnabrueck.de. Acesso em: 05/10/2016.

31 PONCIBÒ, Cristina. Some thoughts on the methodological approach to EC consumer Law Reform. In: Loyola Consumer Law Review, v. 21, n. 3, 2009, p.353-371.

32 Disponível em: www.accademiagiusprivatistieuropei.it. Acesso em: 05/10/2016.

33 GANDOLFI, Giuseppe. (Coord.). Código Europeu dos contratos: projeto preliminar. Livro primeiro: dos contratos em geral. Curitiba, Juruá, 2008.

34 GANDOLFI, Giuseppe. L'unificazione del Diritto dei contratti in Europa: mediante o senza la legge? In: Rivista di Diritto Civile, n. 2, 1993, p. 149-158.

35 MCGREGOR, Harvey. Contract code: proyecto redactado por encargo de la Law Comission inglesa. Barcelona: Bosch, 1997.

36 Disponível em: www.common-core.org. Acesso em: 05/10/2016.

37 PEREIRA, Teresa Silva. Op. cit. 
baseia em questionários e na definição de breves conceitos, em comparação com os $\mathrm{PECL}^{38}$, que assumem estrutura parecida com a de uma compilação.

Em 2007, o SGECC e o grupo Acquis publicaram os Princípios, as Definições e as regras como modelo do Direito privado europeu, chamado de DCFR (Draft Common Frame of Reference $)^{39}$. Sua publicação teria servido de resposta aos Planos da Comissão Europeia para o desenvolvimento de um Direito Contratual Europeu mais coerente ${ }^{40}$. Sua finalidade, contudo, permanece incerta, vez que carrega todas as críticas dos projetos anteriores, ou, nas palavras de Bonell, representa "uma caixa de ferramentas" para os trabalhos da Comissão ${ }^{41}$.

Ao lado dessas iniciativas de ordem privada, cujo interesse é mais imediato, também se pode salientar que o Parlamento e o Conselho Europeu, dentro da tradição da Comunidade Europeia de edição de Diretivas ${ }^{42}$ (por exemplo, 93/13/ CEE $^{43}$, 94/47/CE ${ }^{44}$, 97/7/CE ${ }^{45}, 2000 / 31 /$ CE $^{46}$ 2008/48/CE ${ }^{47}, 2008 / 122 /$ CE $^{48}$, 2014/17/ $\left.\mathrm{UE}^{49}\right)$, vinham adotando medidas com vistas a aproximar o Direito Contratual dos Estados-membros e para criar um Direito Contratual Europeu unificado. Como exemplo disso, cite-se o parecer do Comitê Econômico e Social sobre a "Comunicação da Comissão ao Conselho e ao Parlamento Europeu sobre o

38 LANDO, Ole. The Common Core of European Private Law and the Principles of European Contract Law. In: Hastings International and Comparative Law Review, n. 21, Summer 1998, p. 809-823.

39 BAR, Christian von; CLIVE, Eric; SCHULTE-NÖLKE, Hans. (Ed.). Principles, Definitions and Model Rules of European Private Law Draft Common Frame of Reference (DCFR). Munich: Sellier, 2009; FAUVARQUE-COSSON, Bénédicte. (Dir.). Projet de Cadre Commun de Référence: Principes Contractuels Communs. Paris: Société de Législation Comparée, 2008.

40 BIUKOVIC, L. Anatomy of an experiment: consolidation of EU contractual law. In: University Berkeley Columbia Law Review, v. 41, n. 2, 2008, p. 277-278.

41 BONELL, Michael Joachim. The CISG, European Contract Law and the Development of a World Contract Law. In: American Journal of Comparative Law, n. 56. Winter 2008, p. 15.

42 BIUKOVIC, L. Op. cit., p. 287-288.

43 Relativa às cláusulas abusivas em contratos celebrados com consumidores. Disponível em: http://eur-lex.europa. eu/legal-content/PT/TXT/PDF/?uri=CELEX:31993L0013\&rid=5. Acesso em: 05/10/2016.

44 Relativa à proteção dos adquirentes quanto a certos aspectos dos contratos de aquisição de um direito de utilização a tempo parcial de bens imóveis. Disponível em: http://eur-lex.europa.eu/legal-content/PT/TXT/PDF/?uri=CELEX: 31994L0047\&rid=6. Acesso em: 05/10/2016.

45 Relativa à proteção dos consumidores em matéria de contratos à distância. Disponível em: http://eur-lex.europa. eu/legal-content/PT/TXT/PDF/?uri=CELEX:31997L0007\&rid=9. Acesso em: 05/10/2016.

46 Relativa ao comércio eletrônico. Disponível em: http://eur-lex.europa.eu/legal-content/PT/TXT/PDF/?uri=CELEX:3 2000L0031\&rid=11. Acesso em: 05/10/2016.

47 Relativa a contratos de crédito a consumidores. Disponível em: http://eur-lex.europa.eu/legal-content/PT/TXT/PD F/?uri=CELEX:32008L0048\&rid=5. Acesso em: 05/102/106.

48 Relativa a proteção do consumidor relativamente a determinados aspectos dos contratos de utilização periódica de bens, de aquisição de produtos de férias de longa duração, de revenda e de troca. Disponível em http://eur-lex. europa.eu/legal-content/PT/TXT/PDF/?uri= CELEX:32008L0122\&rid=7. Acesso em: 05/10/2016.

49 Relativa aos contratos de crédito aos consumidores para imóveis de habitação. Disponível em: http://eur-lex. europa.eu/legal-content/PT/TXT/PDF/?uri=CELEX:32014L0017\&qid= 1475672536446\&from=PT. Acesso em: 05/10/2016. 
direito europeu dos contratos" em que expressamente se afirma a necessidade de preservação da ordem pública socioeconômica europeia, sob o controle de juízes nacionais e especialmente protetivas dos consumidores e descritivas dos contratos transfronteiriços ${ }^{50}$.

Além de todos estes exemplos, existe, ainda, a possibilidade de aproximação dos Direitos nacionais pela construção jurisprudencial da Corte de Justiça ${ }^{51}$.

Embora inexistam codificações gerais, o resultado desta efervescência criativa é, então, construção de um ambiente de normatividade complexa, em que diferentes atores internacionais, manejando diferentes fontes e instrumentos normativos, criam um cenário de profunda densidade normativa capaz de engendrar algo desconhecido de outros processos de integração econômica: um Direito Contratual Europeu.

Este movimento, portanto, é justamente o que tem sido descrito como a "europeização" do Direito dos contratos, motivado não apenas por questões econômicas (integração econômica e ajuste do Mercado), mas também culturais ${ }^{52}$. Embora ainda hoje seja majoritariamente centrado em matéria contratual de consumo ${ }^{53}$, podem ser projetados avanços em outras áreas da atividade negocial: contratos de objeto imoral ${ }^{54}$, interpretação dos contratos comerciais ${ }^{55}$, remédios contratuais ${ }^{56}$, contratos de compra e venda ${ }^{57}$.

Nos últimos anos, contudo, a Europa estaria "estagnada, sem forças para avançar ${ }^{\prime \prime 5}$. Este cenário seria fruto de crises exógenas (crise econômica americana

50 EUROPA. Comitê Econômico e Social. Parecer do Comité Económico e Social sobre a "Comunicação da Comissão ao Conselho e ao Parlamento Europeu sobre o direito europeu dos contratos". In: Jornal Oficial das Comunidades Européias. 07 out. 2002, C241/1-7.

51 FRADERA, Véra Maria Jacob de. Reflexões sobre a contribuição do Direito comparado para a elaboração do Direito comunitário. Belo Horizonte: Del Rey, 2010, p. 243-245; 311-322.

52 TWIGG-FLESNER, Christian. The europeanisation of contract Law. New York: Routledge-Cavendish, 2008, p. 181-193.

53 MORAIS, Fabíola. Aproximação do Direito Contratual dos Estados-membros da União Européia. Rio de Janeiro: Renovar, 2007, p. 305-306. Para a Diretiva sobre direito dos consumidores, vide: http://eur-lex.europa.eu/legalcontent/PT/TXT/PDF/?uri=CELEX: 32011L0083\&from=PT. Acesso em: 05/10/2016.

54 Projeto do Common-Core. Disponível em: http://www.common-core.org/node/79. Acesso em: 05/10/2016.

55 Projeto do Common-Core. Questionário disponível em: http://www.common-core.org/sites/default/files/uploaded/ docs/QuestionnairelnterpretationOct2012.pdf. Acesso em: 05/10/2016.

56 Projeto do Common-Core. Questionário disponível em: http://www.common-core.org/sites/default/files/uploaded/ docs/QuestionnaireRemediesInContractLaw2011.pdf. Acesso em: 05/10/2016.

57 Projeto da Academia de Pávia. Inteiro teor: http://www.accademiagiusprivatistieuropei.it. Acesso em: 05/10/2016.

58 ACCIOLY, Elizabeth. As fraturas do velho continente: uma radiografia da União Europeia. Revista da Secretaria do Tribunal Permanente de revisão do Mercosul, ano 4, n. 8, agosto 2016, p. 17. 
e guerra da Síria) e endógenas (crise migratória e suas variadas repercussões) ${ }^{59}$. É neste contexto geral que desponta o movimento do Brexit, cujas possíveis repercussões para o Direito Contratual Europeu devem ser apreciadas.

\section{O BREXIT E AS CONSEQUÊNCIAS PARA O DIREITO CONTRATUAL EUROPEU}

Ainda que não se precise aceitar a ideia de estagnação, entende-se que o processo de integração europeu parece ter perdido sua velocidade inicial. Como destaca Díaz Labrano, a integração econômica pressupõe o desejo de fazer parte de um projeto comum que, embora traga benefícios, atribui aos Estados uma série de obrigações ${ }^{60}$.

A grande dificuldade deste tipo de projeto é transformar os objetivos amplos, e algumas vezes muito ambiciosos, em medidas práticas que possam vincular a política de cada Estado. No cerne dessas dificuldades estão não só as diferenças culturais típicas (como a concepção de que a ordem jurídica nacional é uma expressão cultural $\left.{ }^{61}\right)$, como questões políticas mais amplas.

Alguns desses questionamentos são aqueles trazidos por momentos de crise, como as destacadas anteriormente, em que a grande meta de integração fica mais difícil de ser enxergada. Para a população, por exemplo, que enfrenta a dificuldade de se encaixar nas novas exigências do mercado, é sempre mais fácil acreditar no discurso de que seu emprego foi roubado por estrangeiros.

O momento histórico vivido pela Europa é, portanto, muito distinto daquele em que foi gerado o Tratado constitutivo. As metas de solidariedade e cooperação, que pressupõem ajustes econômicos, jurídicos e políticos internos, tendem a ser entendidas como remédios amargos (e, portanto, questionáveis), quando a recessão ou as ondas migratórias rompem as fronteiras europeias.

Embora se possam compreender as dificuldades enfrentadas pela Europa, o que de fato surpreendeu o mundo foi a iniciativa britânica de propor o desmonte

59 ACCIOLY, Elizabeth. As fraturas do velho continente: uma radiografia da União Europeia. Revista da Secretaria do Tribunal Permanente de revisão do Mercosul, ano 4, n. 8, agosto 2016, p. 12-18.

60 DÍAZ LABRANO, Roberto Luiz. La salida de un Estado miembro en el proceso de integración. El Reino Unido y la Unión Europea. Revista da Secretaria do Tribunal Permanente de revisão do Mercosul, ano 4, n. 8, agosto 2016, p. 42.

61 MORAIS, Fabíola. Aproximação do Direito Contratual dos Estados-membros da União Européia. Rio de Janeiro: Renovar, 2007, p. 23. 
parcial do bloco. Esta perplexidade é resultante, em grande medida, da forma como o Reino Unido se comportou no processo de integração europeu: o "status especial" que lhe havia sido concedido seria fiador de sua permanência na União ${ }^{62}$.

Em outros termos, a aceitação de que o Reino Unido se recusasse a fazer parte da integração mais estreita, permanecendo alheio à Zona Euro e ao acordo Schengen de controle de fronteiras, por exemplo, faria parte de um ajuste que permitiria a manutenção do bloco. Não só isso, várias exigências britânicas, especialmente aquelas relacionadas à atual crise humanitária, haviam sido aceitas pela União.

Ainda que se possa questionar o fundamento da decisão do Brexit, o processo de desligamento da União não parece ser simples, especialmente para o Estado membro que precisará promover a revogação ou denúncia da estrutura normativa criada para sua permanência na União. Em outros termos, o Brexit exigirá o esforço, especialmente dos britânicos, de revisarem e reformularem sua ordem jurídica interna.

Em termos muito simplistas, para que o Reino Unido partilhasse as mencionadas metas típicas do processo de integração, foi necessário que se inscrevesse na construção do chamado Direito Europeu, ou seja, que promovesse a ratificação e a promulgação de uma série de tratados internacionais. Além deles, negociados diretamente pelo Reino Unido, a própria competência delegada pelos britânicos à União fez com que esta assumisse uma série de compromissos internacionais em nome dos Estados-membros.

Assim, os britânicos estarão diante da necessidade de refutarem compromissos internacionais que tomaram para ingressar e permanecer no bloco, assim como aqueles tomados, pelo bloco, enquanto lá estiveram.

Também se deve lembrar que estas alterações promovidas no seio da ordem jurídica britânica precisarão ser localizadas, suas repercussões estudadas e as medidas substitutivas tomadas. Em outros termos: o grau de integração é tão estreito que não basta a mera denúncia dos Tratados eventualmente celebrados, isto poderia criar lacunas com as quais os britânicos não conseguiriam lidar em um curto espaço de tempo.

62 DÍAZ LABRANO, Roberto Luiz. La salida de un Estado miembro en el proceso de integración. El Reino Unido y la Unión Europea. Revista da Secretaria do Tribunal Permanente de revisão do Mercosul, ano 4, n. 8, agosto 2016 , p. 47. 
Além dos tratados, existem os mecanismos tipicamente europeus: as Diretivas e os Regulamentos. Enquanto aquelas estabelecem as diretrizes que devem ser adotadas internamente pelos Estados membros (por meio de reformas legislativas), estes são atos da própria União, obrigatórios para os Estados membros.

Como se viu, existe uma série de Diretivas em matéria contratual que já transformou (modificou) o Direito inglês. Essas diretivas serão reavaliadas também? A concretização do Brexit traria alguma espécie de repristinação? Ou eventualmente estas modificações serão mantidas, mantendo-se, também, algum nível de harmonização legislativa pós-Brexit? Embora, portanto, as Diretivas não precisem ser revogadas, surge a indagação se permitiriam aos britânicos a continuidade de seus efeitos na legislação interna.

Talvez a questão mais sensível seja justamente a existência de Regulamentos. Sabe-se que haverá um prazo de dois anos para a negociação dos termos de saída do Reino Unido da União (nos termos do art. 50 do Tratado da União Europeia). Neste prazo os ajustes em termos de eventual denúncia de tratados e modificações exigidas pelas Diretivas devem ser avaliados e, em algum grau, negociados e implementados. No que se refere aos Regulamentos, no entanto, o desligamento do Reino Unido causará sua imediata perda de vigência no território do Estado membro retirante. Em um cenário aterrador, seria toda uma ordem normativa, construída por anos e que influencia variados aspectos da vida do cidadão, deixando de existir do dia para a noite.

Este é o caso de importantes iniciativas em matéria contratual. Cite-se, inicialmente, a Convenção de Roma I que regula o sistema de escolha do Direito aplicável aos contratos internacionais, prevendo, inclusive, regra subsidiária quando os contratantes não definiriam esta escolha. Portanto, todo o sistema aplicável aos contratos europeus que os torna mais seguros, do ponto de vista de Direito aplicável, deixaria de ser aplicado aos contratos ingleses, tão logo fosse implementado o Brexit. A mesma situação pode ser esperada em relação ao regulamento Bruxelas I, que trata de jurisdição internacional.

No cenário dos Tratados, por outro lado, pode-se citar também importante exemplo contratual: a Convenção de Viena de 1980 sobre compra e venda internacional de mercadorias (CISG). O Reino Unido, ao contrário de seus parceiros 
europeus, não aderiu a este padrão internacional de regulamentação contratual. Em não o fazendo, haverá importante lacuna que precisará ser preenchida: estes tradicionais parceiros contratuais precisarão definir qual o direito regerá suas importações e exportações. Seria necessário o retorno aos mecanismos de conflitos de leis ("Direito Internacional Privado")?

Tomando estes fatos em consideração, é possível supor que o Brexit possa causar considerável incerteza sobre o próprio marco regulatório aplicado aos contratos que venham a ser celebrados entre partes europeias e inglesas. Este grau de incerteza é tão evidente que se desdobra desde o Direito aplicável ao contrato, o regulamento contratual aplicável aos contratos de compra e venda internacional de mercadorias e às regras de jurisdição nacional aplicáveis a estes contratos.

Ao lado destes questionamentos há, também, a noção de que, uma vez formalizada a saída do reino Unido, ele passará a ser um "terceiro" em seu relacionamento com a Europa. Isto tem repercussões que vão além de necessitar negociar novos termos para todo tema que anteriormente era tratado via Direito Europeu (por exemplo, desde as questões de vistos, até a previdência social, o acesso à educação superior e a possibilidade de trabalho na Europa), como suas negociações comerciais serão travadas dentro de um novo marco: o da Organização Mundial do Comércio (OMC). Outro ponto de destaque é que, caso o Reino Unido resolva promover o seu reingresso na União Europeia, ele precisaria renegociar todos os termos de ingresso, assim como reincorporar os instrumentos normativos internacionais que tiver revogado ou denunciado.

Em se confirmando a retirada do Reino Unido, nada impede, contudo, que ele mantenha a vigência das normas comunitárias enquanto não forem substituídas, criando uma regra de transição para regular este período pós-Europa mais imediato. O atual cenário de harmonização e uniformização em matéria contratual estaria, assim, congelado, pelo menos por um determinado tempo. Como se sabe, contudo, a harmonização e a uniformização são movimentos que não são pensados para as soluções temporárias, eles são projetados para serem permanentes. Reverter processos harmonizantes/uniformizantes é algo que não é novidade, mas sempre ocorreu em ambiente nacional, expondo, no máximo, o Estado a sua 
responsabilização internacional (por exemplo, o caso da Lei Uniforme de Genebra, alterada por legislação nacional brasileira). O que se questiona é como o processo de criação de um Direito Contratual Europeu subsistiria.

Ao lado das repercussões normativas, há, igualmente, o fato de que inúmeras relações negociais de longa duração, acordadas sob a égide do Direito Europeu, permanecerão em vigor. Estas relações, eventualmente, sofrerão consequências que podem ir além da incerteza do quadro normativo, mas das mudanças fáticas e econômicas (tarifárias ou empregatícias, por exemplo) que podem causar abalo em sua execução. Neste sentido, o Brexit poderia ser considerado evento que justificaria a extinção destes vínculos (force majeure)? Ou eventualmente ela dará ensejo à invocação de cláusulas de hardship (ou eventualmente MAC clauses "material adverse change") que imponham a renegociação dos termos contratuais? Surgem, aqui, portanto, questionamentos concretos sob a incidência dos efeitos no Brexit nos próprios ajustes contratuais. Como se sabe, os tribunais europeus em geral e os ingleses em especial são muito reticentes em intervir em contratos.

Além de todos os potenciais prejuízos, pode-se somar outro para aqueles Estados membros que permanecerem: a aproximação entre o Civil Law e o Common Law sofrerá, por certo, desaceleração. Se esta era uma das facetas mais promissoras e criativas do processo de consolidação do Direito contratual europeu, talvez o Brexit venha produzir a vítima exemplar dos desacertos políticos da integração.

Todos estes questionamentos, ainda que em fase prospectiva, servem para se avaliar e repensar as propostas do movimento de integração mais importante da América do Sul. Eis o que se passará a promover.

\section{MERCOSUL E A FORMAÇÃO DE UM DIREITO CONTRATUAL COMUNITÁRIO.}

Ao contrário do movimento europeu, a tentativa de criação de um Direito Contratual dos países membros do MERCOSUL é incipiente, especialmente porque poucos são os instrumentos originários do MERCOSUL sobre a matéria.

Esta constatação pode, em um primeiro momento, causar estranheza, uma vez que o MERCOSUL tem por objetivo a harmonização legislativa nos diferentes 
Estados membros como parte do processo de integração econômica. Neste sentido, aliás, dispõe, expressamente, o artigo $1^{\circ}$ do Tratado de Assunção, marco normativo criador do Mercado Comum do Sul, ser "compromisso dos Estados Partes de harmonizar suas legislações, nas áreas pertinentes, para lograr o fortalecimento do processo de integração." ${ }^{63}$.

Esta mesma intenção está, mais uma vez, presente no Protocolo de Ouro Preto, que estrutura a atual configuração do bloco, ao determinar que as normas produzidas pelo MERCOSUL sejam obrigatórias para os Estados membros (art. $9^{\circ}$ ) e que devam ser adotadas as medidas necessárias para cumprimento das normas do MERCOSUL nos respectivos territórios (art. 38).

Também é no Protocolo de Ouro Preto que já se percebe outra característica fundamental em relação à criação do Direito Comunitário no MERCOSUL: suas normas precisam ser internalizadas por todos os respectivos Estados membros (art. 40 e 42) ${ }^{64}$. Este detalhe faz, então, com que além da negociação internacional para a harmonização legislativa, ela seja acompanhada das discussões políticas internas de cada país.

Além disso, como os Protocolos do MERCOSUL dependem da adesão unânime (art. 40 do Protocolo de Ouro Preto), a entrada em vigor de cada Protocolo pode se arrastar indefinidamente, a depender das idiossincrasias dos sistemas políticos internos de cada país ${ }^{65}$. Some-se a isso que as decisões do MERCOSUL também são tomadas por unanimidade, o que pode produzir considerável atraso desde sua discussão.

Também se deve ter em mente que a estrutura institucional do MERCOSUL é intergovernamental, inexistindo uma autoridade central incumbida de promover a integração. Apesar disso, o MERCOSUL dispõe de instrumentos normativos próprios (como as Decisões do Conselho Mercado Comum e as Resoluções do Grupo Mercado Comum) para promover a harmonização necessária.

Pode-se afirmar, então, que a tentativa de aprofundar a harmonização das legislações nacionais dos Estados membros do MERCOSUL ainda não resultou em

63 Disponível em: http://www.mdic.gov.br/arquivos/dwnl_1270491919.pdf. Acesso em: 1\%/10/ 2016.

64 Disponível em: http://www.mercosur.int/msweb/SM/Normas/PT/CMC_1994_OuroPreto.pdf. Acesso em: $1 \% / 10 / 2016$

65 Este tema, por exemplo, já foi objeto de debate no órgão de solução de controvérsias do MERCOSUL, em que a Argentina argumentava a demora brasileira em incorporar instrumentos do MERCOSUL (Laudo VII). Disponível em: http://www.mercosur.int/msweb/portal\% 20intermediario/pt/controversias/VII\%20LAUDO.pdf. Acesso em: 04/10/2016. 


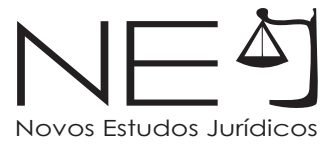

um Direito Contratual comunitário em sentido estrito, como seria de se esperar. Isto, aliás, se deve a variadas razões.

(i) Em primeiro lugar, deve-se destacar que o MERCOSUL, ao contrário da União Europeia, não alcançou, ainda, a plena liberdade de circulação de pessoas, bens, capitais e serviços; nem iniciou qualquer processo de harmonização e uniformização de políticas econômicas e monetárias.

Atualmente, aliás, o MERCOSUL é descrito como uma União Aduaneira imperfeita, uma vez que, embora exista, formalmente, uma tarifa externa comum (TEC), muitas são as exceções permitidas e utilizadas pelos Estados membros. $\mathrm{O}$ Brasil está autorizado, por exemplo, pelo próprio MERCOSUL ${ }^{66}$, a manter, até 31 de dezembro de 2021, uma lista de 100 itens como exceções à TEC. Pode-se, pois, facilmente concluir que qualquer processo de aprofundamento da integração econômica do MERCOSUL está adiado até 2021.

(ii) A segunda dimensão de análise é, justamente, a política. Uma indagação corriqueiramente apresentada é se o MERCOSUL pretende vir a ser uma "União Europeia" da América do Sul. A resposta que se der a esta indagação condiciona, como se sabe, a própria ideia de formação de um Direito Comunitário. Se se pensar no MERCOSUL como uma "União Europeia em desenvolvimento"67, a situação atual de ausência de um Direito Comunitário e, mesmo, os escassos passos dados em prol da uniformização do Direito Contratual podem parecer mais próximos de um fracasso. Deve-se, contudo, levar em conta que não só a história é distinta nestes dois blocos, como o desenvolvimento econômico os distancia.

O processo de formação da União Europeia completará 60 (sessenta) anos de existência. Algumas de suas raízes, aliás, são mais antigas (Comunidade do Carvão e do Aço de 1951). O projeto de integração europeu teve, claramente, como um de seus pilares servir de argumento dissuasório para futuros conflitos bélicos. Adicionalmente, deve-se lembrar de que as economias dos diferentes Estados membros não só eram muito distintas, como não necessariamente pautadas nas mesmas estratégias comerciais. O MERCOSUL, por sua vez, é projeto

66 Decisão Conselho Mercado Comum no 26/15. O Conselho Mercado Comum (CMC) conduz a política do bloco e a tomada de decisões, é composto pelos chanceleres dos Estados membros.

67 LORENZETTI, Ricardo. Sistema jurídico del Mercosur. In: MARQUES, Cláudia Lima; ARAÚJO, Nadia. O novo Direito Internacional: estudos em homenagem a Erik Jayme. Rio de Janeiro: Renovar, 2005, p. 645. 
muito mais recente (o Tratado de Assunção é de 1991) e, embora pensado como instrumento geopolítico, não se propunha evitar mais conflitos bélicos (mais distantes da realidade sul-americana), mas aproximaria países com pautas de exportação e estratégias comerciais muito similares. A economia da integração, portanto, nestes dois exemplos, não é a mesma.

Outro detalhe que se deve atentar é que o próprio sucesso do projeto europeu é traduzido na atual crise. O contínuo crescimento do bloco, com a incorporação de cada vez maior número de mercados nacionais, parece ter causado parte de seus problemas. A Europa, vista a partir de fora, apresenta "duas velocidades"68. um mercado cada vez maior e livre, mas, ao mesmo tempo, cada vez mais burocratizado e normatizado (e, portanto, impositivo). Faz sentido, portanto, a desconfiança e o descontentamento de alguns Estados insatisfeitos com o nível de intervenção supranacional. O cidadão europeu está ciente e é objeto das Decisões do Bloco, a política, antes nacional, se transfere para a realidade supranacional. Novas fontes de tensão e descontentamento estão disponíveis a cada momento e a ameaça final acaba sendo a definitiva: o desmonte do bloco. Este seria o preço da democratização supraestatal.

NoMERCOSUL, poroutrolado, a realidadeéoutra. Ograu deinstitucionalização é, ainda, muito escasso e acaba se resumindo a discussões políticas fugazes e, aparentemente, remotas do dia a dia do eleitorado nacional. Adicionalmente, normas do MERCOSUL pouco aparecem para os nacionais de seus Estados membros, fazendo com que a tensão política acabe, ainda, encontrando espaço apenas local. Além disso, a demora na concretização das políticas mercosulinas dilui o espaço de crítica e contestação, além de essas políticas serem muito pouco invasivas da vida privada.

Por fim, deve se destacar a instabilidade do bloco: o cidadão comum desconfia de sua permanência. Não só o fator temporal e o pouco impacto das medidas devem ser levados em conta, mas também a própria instabilidade dos regimes políticos latino-americanos. O mais recente foco de tensão foi, justamente, o ingresso da República Bolivariana da Venezuela no bloco. Lembre-se que este ingresso só foi possível por meio da suspensão da República do Paraguai no bloco (o Parlamento 68 LORENZETTI, Ricardo. Sistema jurídico del Mercosur. In: MARQUES, Cláudia Lima; ARAÚJO, Nadia. O novo Direito Internacional: estudos em homenagem a Erik Jayme. Rio de Janeiro: Renovar, 2005, p. 646. 


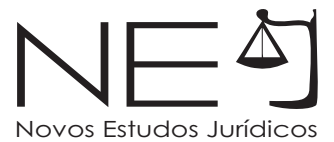

paraguaio era o único que se opunha à ratificação da adesão da Venezuela). A tensão foi provisoriamente afastada quando, depois de intensas negociações, o Paraguai aprovou a adesão da Venezuela e foi reintegrado ao bloco. A deterioração do ambiente político nacional venezuelano, entretanto, cobrou o seu preço: a Venezuela é ameaçada com a mesma suspensão do bloco, enquanto um movimento dos demais Estados membros a afastou da presidência temporária do MERCOSUL.

Como se pode perceber, então, a institucionalização do MERCOSUL ainda é muito dependente da realidade política nacional de cada um de seus Estados membros, problema que se agrava com os alinhamentos ideológicos extremados na região.

(iii) Um terceiro nível de análise é, por fim, o jurídico. Em um primeiro momento parece ser significativo o fato de os países membros adotarem diferentes perspectivas em relação ao processo de ratificação dos Tratados e sua prevalência ou não sobre o Direito interno. Enquanto a Argentina, o Paraguai e a Venezuela adotam em suas constituições (art. 75, 22 da Constituição argentina ${ }^{69}$, art. 137 da Constituição paraguaia ${ }^{70}$ e art. 153 da Constituição venezuelana ${ }^{71}$ ) mecanismos que prometem a superioridade de normas internacionais sobre a legislação nacional, o Brasil e o Uruguai insistem na necessidade de nacionalização. O Uruguai, como o Brasil, não tem norma constitucional que solucione o conflito entre a norma internacional e a norma interna. Em ambos os casos, também, a jurisprudência confere a Tratados e Leis a mesma hierarquia.

Um segundo ponto a se levar em consideração é a existência, no âmbito contratual, de um Direito comunitário originário. Na tentativa de construção de um tecido normativo contratual coerente, alguns tratados de matéria contratual foram celebrados, dentre os quais podem ser destacados: o Protocolo de Buenos Aires (1994) sobre jurisdição internacional contratual; o Protocolo de Santa Maria sobre jurisdição internacional em matéria de relações de consumo (1996); o Protocolo de Montevidéu sobre o comércio de serviços (1997); o Acordo de Buenos Aires (1998) sobre arbitragem comercial internacional e o Acordo de Buenos Aires (2002) sobre transporte internacional de cargas $^{72}$.

69 Disponível em: http://www.casarosada.gob.ar/images/stories/constitucion-nacional-argentina.pdf. Acesso em: $1 \% 10 / 2016$.

70 Disponível em: http://www.oas.org/juridico/spanish/par_res3.htm. Acesso em: 10/10/2016.

71 Disponível em: https://www.oas.org/dil/esp/Constitucion_Venezuela.pdf. Acesso em: 1\%/10/2016.

72 Disponível em: http://www.mre.gov.py/tratados/public_web/ConsultaMercosur.aspx. Acesso em: 10/10/2016. 
Estes seriam, então, os principais instrumentos normativos do MERCOSUL, em âmbito contratual, que poderiam servir de semente para a criação de um Direito Contratual do MERCOSUL. O Protocolo de Buenos Aires (1994), o Protocolo de Montevidéu (1997) e o Protocolo de Buenos Aires (1998) foram ratificados por todos os Estados membros e, portanto, estariam em vigor. Isso ocorre, contudo, com alguma diferença de anos: o Protocolo de Montevidéu, por exemplo, só foi ratificado por todos os Estados em 2014.

O Acordo de Buenos Aires (2002), por outro lado, foi ratificado apenas pelo Brasil. Já o Protocolo de Santa Maria (1996) não chegou a ser ratificado por qualquer dos Estados parte. Nenhum deles, portanto, está em vigor. Também se deve mencionar o pouco debate regional em torno da possibilidade e da viabilidade de criação de restatement contratual (Princípios Latino-americanos de Direito dos Contratos). Embora o projeto até mesmo exista, sua iniciativa ainda é restrita a pequeno grupo de acadêmicos e os trabalhos são pouco públicos.

Estes dados revelam, então, que o material normativo para a constituição de um Direito Contratual do MERCOSUL é superficial e sem a pretensão de qualquer generalidade.

(iv) Apesar de todas estas dificuldades, existem outros fatores que tendem a facilitar a criação de um eventual Direito Contratual do MERCOSUL, se e quando este for um projeto do bloco. Em primeiro lugar, deve-se lembrar de que todos os países da região compartilham a formação histórica e similaridade linguística ${ }^{73}$; a tradição ibérica da Civil Law, com conceitos contratuais básicos (força obrigatória dos contratos, boa-fé, etc.) ${ }^{74}$ e tendências doutrinárias e jurisprudenciais compartilhadas ${ }^{75}$.

Destaque-se, ainda, um esforço regional para a diminuição de assimetrias legislativas nacionais, em especial na matéria de contratos internacionais ${ }^{76} \mathrm{e}$ contratos de consumo ${ }^{77}$.

73 OLIVEIRA, Renata Fialho de. Harmonização jurídica no Direito Internacional. São Paulo: Quartier Latin, 2008, p. 180.

74 LORENZETTI, Ricardo. Sistema jurídico del Mercosur. In: MARQUES, Cláudia Lima; ARAÚJO, Nadia. O novo Direito Internacional: estudos em homenagem a Erik Jayme. Rio de Janeiro: Renovar, 2005, p. 659-660.

75 FELDSTEIN DE CÁRDENAS, Sara Lidia. Armonización del derecho contractual del mercosur: ¿una misión imposible? Revista de la Secretaría del Tribunal Permanente de Revisión. Año 4, Nº7, Mayo 2016; p.91-92.

76 FELDSTEIN DE CÁRDENAS, Sara Lidia. Armonización del derecho contractual del mercosur: ¿una misión imposible? Revista de la Secretaría del Tribunal Permanente de Revisión. Año 4, N7, Mayo 2016; p.40-96.

77 GAIO JUNIOR, Antonio Pereira. Proteção consumerista no MERCOSUL: por uma harmonização legal. Revista de la Secretaría del Tribunal Permanente de Revisión. Año 1, № 2, 2013, p. 23-47. 
Outro ponto que merece reflexão é o fato de a região ter alcançado, ainda que de forma indireta, algum nível de uniformização em determinadas matérias contratuais (seja global ou regional). Assim, por exemplo, a Convenção de Nova Iorque de 1958 sobre o reconhecimento e a execução de laudos arbitrais estrangeiros foi ratificada por todos os países membros do MERCOSUL ${ }^{78}$.

Já a Convenção de Viena de 1980 sobre compra e venda internacional de mercadorias (CISG) e a Convenção de Montreal 1999 sobre para unificação de regras atinentes ao transporte aéreo foram ratificadas por todos os países com MERCOSUL, com exceção da República Bolivariana da Venezuela79.

A Convenção de 1978 sobre contrato de transporte internacional de mercadorias pelo mar ("regras de Hamburgo") foi ratificada apenas pelo Paraguai, ainda que o Brasil a tenha assinado ${ }^{80}$. A Convenção da Cidade do Cabo de 2001 sobre garantias internacionais incidentes sobre equipamentos móveis só foi ratificada pelo Brasil ${ }^{81}$. Esta é a mesma situação da Convenção Interamericana do México (1994), CIDIP V, sobre direito aplicável aos contratos internacionais que foi ratificado apenas pela Venezuela82. Por outro lado, a Lei Modelo da UNCITRAL sobre assinaturas eletrônicas serviu de inspiração para a legislação paraguaia ${ }^{83}$, enquanto a Lei Modelo da UNCITRAL sobre comércio eletrônico serviu de inspiração para as legislações paraguaia e venezuelana ${ }^{84}$.

Outras Convenções mais recentes como a Convenção de Nova Iorque 2005 sobre utilização de comunicações eletrônicas em contratos internacionais ${ }^{85}$ e a Convenção de Nova Iorque 2008 para contrato de transporte internacional de mercadorias pelo mar $^{86}$ não foram ratificadas por nenhum dos Estados membros do MERCOSUL.

78 Disponível em: http://www.uncitral.org/uncitral/en/uncitral_texts/arbitration/NYConvention_status.html. Acesso em: 1\%/10/2016.

79 Para dados sobre a CISG - disponível em: http://www.uncitral.org/uncitral/en/uncitral texts/sale_goods/1980CISG status.html. Acesso em: 1\%/10/2016. Para dados sobre a Convenção de Montreal - http://www.icao.int/secretariat/ legal/List\%20of\%20Parties/Mt199_EN.pdf. Acesso em: 1\%/10/2016.

80 Disponível em: http://www.uncitral.org/uncitral/en/uncitral_texts/transport goods/Hamburg_status.html.Acesso em: 1\%10/2016.

81 Disponível em: http://www.unidroit.org/status-2001capetown. Acesso em: 1\%/10/2016.

82 Disponível em: http://www.oas.org/juridico/english/sigs/b-56.html. Acesso em: 10/10/2016.

83 Disponível em: http://www.uncitral.org/uncitral/en/uncitral_texts/electronic_commerce/ 2001Model_status.html. Acesso em: 1\%/10/2016.

84 Disponível em: http://www.uncitral.org/uncitral/en/uncitral_texts/electronic_commerce/ 1996Model_status.html. Acesso em: 1\%/10/2016.

85 Disponível em http://www.uncitral.org/uncitral/en/uncitral_texts/electronic_commerce/ 2005Convention_status. html. Acesso em: 1\%/10/2016.

86 Disponível em: http://www.uncitral.org/uncitral/en/uncitral_texts/transport_goods/rotterdam status.html. Acesso em: $1 \% / 10 / 2016$. 
Pode-se, então, perceber que, ao lado de um Direito Contratual consubstanciado em instrumentos originários do próprio MERCOSUL, existem alguns textos uniformizadores que também podem contribuir para a criação deste Direito Contratual comunitário, ainda que de forma indireta.

Atualmente, contudo, a fragilidade institucional do MERCOSUL e a ausência de instrumentos mais gerais e iniciativas específicas de harmonização contratual fazem supor a inexistência deste Direito Contratual do MERCOSUL. Embora sua criação não seja uma "missão impossível" 87, o atual grau de dificuldade desta missão não é comparável com o cenário europeu.

\section{CONSIDERAÇÕES FINAIS}

A europeização do Direito dos Contratos tem sido descrita como o fenômeno de criação de um Direito Contratual europeu por meio do trabalho desenvolvido por diferentes atores internacionais (públicos e privados) que, manejando instrumentos normativos não ortodoxos, conseguem dar volume normativo criativo a um Direito Contratual, em grande parte, compartilhado pelos países europeus.

O que torna peculiar este processo é, ao contrário do MERCOSUL, a presença de duas tradições contratuais no seio de um mesmo "Direito Comunitário". A potencialidade de soluções contratuais, portanto, sempre teve, neste aspecto e no cenário europeu, a vantagem de buscar soluções em duas matrizes jurídicas distintas. Se, por um lado, esta característica poderia trazer mais dificuldades, de outro o potencial criativo seria duplicado.

Esta, aliás, é uma característica também dos processos de harmonização contratual conduzidos em âmbito global: a forte presença de autores e soluções oriundos da Common Law. Um exemplo aclamado disso é a CISG.

Além disso, ainda que este "Direito Contratual europeu" tenha algum tipo de institucionalização, ela ainda é mais projetada que, propriamente, codificada. A honrosa exceção neste caso são os contratos de consumo, amplamente regulados pela Europa.

O que se deve destacar, então, seria a existência de um ambiente de complexidade normativa, em que não só a busca na identificação de um Direito 87 FELDSTEIN DE CÁRDENAS, Sara Lidia. Armonización del derecho contractual del mercosur: ¿una misión imposible? Revista de la Secretaría del Tribunal Permanente de Revisión. Año 4, Nº7, Mayo 2016; p.91-91. 
comum esteja ocorrendo, mas sua efetiva construção por meio de procedimentos de harmonização normativa. Este movimento, como se viu, não decorre apenas de iniciativas isoladas, mas de esforço acadêmico e político concentrado na busca da criação de um quadro normativo comum.

Embora a velocidade (e sucesso) da ampliação do espaço europeu, seguida das crises econômicas recentes, tenha causado desaceleração desse movimento, nunca se vislumbrou a possibilidade de seu retrocesso.

O Brexit traz, portanto, não só a incerteza do futuro, mas uma ruptura de um projeto de harmonização do Direito Contratual mais amplo. O diálogo, neste sentido, perde um importante contraponto: a Common Law. Além disso, as normas já introduzidas no seio do Ordenamento jurídico britânico, algumas delas com influência mais continental, também tendem a ser extirpadas do Direito inglês.

As muitas incertezas do processo de retirada do Reino Unido só pioram a sensação de que o Direito Contratual Europeu esteja passando por um desmonte. A postura política e as futuras decisões britânicas sobre como conduzir este processo podem agravar ainda mais esta sensação.

Quando o objeto de análise passa para a possível existência e criação de um Direito Contratual comunitário do MERCOSUL, pode-se perceber que existem diversos obstáculos a serem superados.

A estrutura institucional do MERCOSUL é, em um primeiro momento, uma dessas dificuldades. Não só a negociação e a adoção de instrumentos internacionais específicos exigem a unanimidade para aprovação, como sua eficácia fica condicionada à ratificação do instrumento por todos os Estados membros (fazendo influir eventuais dificuldades políticas internas). Além disso, pelo menos no Brasil e no Uruguai, nada impede que eventual norma interna futura possa revogar o Protocolo ratificado (alterando o eventual projeto comum).

Também o MERCOSUL é extremamente aberto às dificuldades políticas internas que cada Estado enfrenta internamente. Neste aspecto, desde a pressão por incentivos tributários (e acréscimos em lista de exceções à TEC), até o próprio alinhamento ideológico dos governantes causam atraso na tomada de medidas que promovam maior integração. 
O cenário só não é de menor harmonização na medida em que: (i) a maior parte dos instrumentos originários do MERCOSUL, em matéria contratual, já foram integralizados por todos os países; (ii) alguns importantes instrumentos internacionais (não originários do MERCOSUL) foram integralizados pela maior parte dos Estados membros; e (iii), principalmente, porque os países da região compartilham uma tradição de concepção do Direito, de suas fontes e de seus princípios (aprofundada, em boa medida, pelo trabalho da doutrina e da jurisprudência local).

A comparação dos modelos, de seu grau de institucionalização e seus objetivos mais imediatos ajuda a compreender não só o esforço que demanda a construção de um Direito Contratual comunitário, mas as dificuldades da excessiva institucionalização quando um de seus membros decide partir.

O exemplo do Brexit, então, é mais uma lição a ser aprendida no processo de integração: o sucesso também tem seu preço, quando as metas deixam de ser comuns.

\section{REFERÊNCIAS DAS FONTES CITADAS}

ACADEMIA DE PAVIA. Projeto de Código Europeu dos Contratos. Compra e venda. Disponível em: http://www.accademiagiusprivatistieuropei.it/. Acesso em: 19.set.2017.

ACCIOLY, Elizabeth. As fraturas do velho continente: uma radiografia da União Europeia. In: Revista da Secretaria do Tribunal Permanente de revisão do Mercosul, ano 4, n. 8, p. 1218, agosto 2016.

ALPA, Guido. Les nouvelles frontières du droit des contrats. In: Revue internationale de droit comparé. v. 50, n. 4. p. 1015-1030. out./dez. 1998

AMISSAH, Ralph. The Autonomous Contract: Reflecting the borderless electronic-commercial environment in contracting. Disponível em: http://www.jus.uio.no/lm//the.autonomous. contract.07.10.1997.amissah/doc.html. Acesso em: 01.out.2017.

ARGENTINA. Constitución Nacional. Disponível em: http://www.casarosada.gob.ar/images/ stories/constitucion-nacional-argentina.pdf. Acesso em: 01.out.2017.

BAR, Christian von; CLIVE, Eric; SCHULTE-NÖLKE, Hans. (Ed.). Principles, Definitions and Model Rules of European Private Law Draft Common Frame of Reference (DCFR). Munich: Sellier, 2009.

BASSO, Maristela. Curso de Direito Internacional Privado. São Paulo: Atlas, 2009.

BIUKOVIC, Ljljana. Anatomy of an experiment: consolidation of EU contractual law. In: University Berkeley Columbia Law Review, v. 41, n. 2. p. 277-278. 2008. 
BONELL, Michael Joachim. The CISG, European Contract Law and the Development of a World Contract Law. In: American Journal of Comparative Law, n. 56, p. 01-28. Winter 2008.

. The UNIDROIT Principles of International Commercial Contracts and the Principles of European Contract Law: Similar Rules for the Same Purposes? In: Uniform Law Review, p. 229-246. 1996.

CARBONARA, Emanuela; PARISI, Francesco. The Economics of Legal Harmonization. In: German Working Papers in Law and Economics, n. 1, 2006, p. 02-30.

CONFERÊNCIA DA HAIA. Princípios da Haia sobre a escolha do Direito aplicável a contratos comerciais internacionais. Disponível em: https://www.hcch.net/pt/instruments/ conventions/full-text/?cid=135. Acesso em: 18. jan. 2017.

DÍAZ LABRANO, Roberto Luiz. La salida de un Estado miembro en el proceso de integración. El Reino Unido y la Unión Europea. In: Revista da Secretaria do Tribunal Permanente de revisão do Mercosul, ano 4, n. 8, p. 41-63. agosto 2016.

EUROPA. Comissão Lando. Principles of European Contract Law. Disponível em: www.jus. uio.no/lm/eu.contract.principles.parts.1.to.3.2002/ toc.html. Acesso em: 05.out.2017.

Comitê Econômico e Social. Parecer do Comité Económico e Social sobre a "Comunicação da Comissão ao Conselho e ao Parlamento Europeu sobre o direito europeu dos contratos". In: Jornal Oficial das Comunidades Européias. C241/1-7. 07 out. 2002.

Diretiva 93/13/CEE. Relativa às cláusulas abusivas em contratos celebrados com consumidores. Disponível em: http://eur-lex.europa.eu/legal-content/PT/TXT/PDF/?uri=CELE X:31993L0013\&rid=5. Acesso em: 05 out. 2017.

Diretiva 94/47/CE. Relativa à proteção dos adquirentes quanto a certos aspectos dos contratos de aquisição de um direito de utilização a tempo parcial de bens imóveis. Disponível em: http://eur-lex.europa.eu/legal-content/PT/TXT/PDF/?uri=CELEX:31994L0047 \&rid=6. Acesso 05.out.2017.

Diretiva 97/7/CE. Relativa à proteção dos consumidores em matéria de contratos à distância. Disponível em: http://eur-lex.europa.eu/legal-content/PT/TXT/PDF/?uri=CELEX:319 97L0007\&rid=9. Acesso 05.out.2017.

Diretiva 2000/31/CE. Relativa ao comércio eletrônico. Disponível em: http://eurlex.europa.eu/legal-content/PT/TXT/PDF/?uri=CELEX:32000L0031 \&rid=11. Acesso em: 05.out.2017.

Diretiva 2008/48/CE. Relativa a contratos de crédito a consumidores. Disponível em: http://eur-lex.europa.eu/legal-content/PT/TXT/PDF/?uri=CELEX :32008L0048\&rid=5. Acesso em: 05.out.2017.

Diretiva 2008/122/CE. Relativa a proteção do consumidor relativamente a determinados aspectos dos contratos de utilização periódica de bens, de aquisição de produtos 
de férias de longa duração, de revenda e de troca. Disponível em http://eur-lex.europa.eu/ legal-content/PT/TXT/PDF/?uri=CELEX:32008L0122\&rid=7. Acesso em: 05.out.2017.

Diretiva 2011/83/UE. Relativa aos direitos dos consumidores. Disponível em: http:// eur-lex.europa.eu/legal-content/PT/TXT/PDF/?uri=CELEX:32011L0083\&from=PT. Acesso em: 05.out.2017.

Diretiva 2014/17/UE. Relativa aos contratos de crédito aos consumidores para imóveis de habitação. Disponível em: http://eur-lex.europa.eu/legal-content/PT/TXT/ PDF/?uri=CELEX:32014L0017\&qid = 1475672536446\&from=PT. Acesso em: 05.out.2017.

Tratado de Lisboa. Disponível em: http://www.lisbon-treaty.org/wcm/the-lisbontreaty/treaty-on-european-union-and-comments/title-6-final-provisions/137-article-50. html. Acesso em: 05.out.2017.

FAUVARQUE-COSSON, Bénédicte. (Dir.). Projet de Cadre Commun de Référence: Principes Contractuels Communs. Paris: Société de Législation Comparée, 2008.

FRADERA, Véra Maria Jacob de. Reflexões sobre a contribuição do Direito comparado para a elaboração do Direito comunitário. Belo Horizonte: Del Rey, 2010.

FRANÇA. Ordonnance n 2016-131 de 10 de fevereiro de 2016. Disponível em: https://www. legifrance.gouv.fr/affichTexte.do;jsessionid=604A2DE2CD769 D2E0BF1467515AD50FD.tpdila 10v_3?cidTexte=JORFTEXT000032004939\&categorieLien=id. Acesso 05.out.2017.

FELDSTEIN DE CÁRDENAS, Sara Lidia. Armonización del derecho contractual del mercosur: ¿una misión imposible? In: Revista de la Secretaría del Tribunal Permanente de Revisión. Año 4, N07. p.40-96. Mayo 2016.

GAIO JUNIOR, Antonio Pereira. Proteção consumerista no MERCOSUL: por uma harmonização legal. In: Revista de la Secretaría del Tribunal Permanente de Revisión. Año 1, No 2, p. 2347, 2013.

GANDOLFI, Giuseppe. (Coord.). Código Europeu dos contratos: projeto preliminar. Livro primeiro: dos contratos em geral. Curitiba, Juruá, 2008.

. L'unificazione del Diritto dei contratti in Europa: mediante o senza la legge? In: Rivista di Diritto Civile, n. 2, p. 149-158, 1993.

GOODE, Roy; KRONKE, Herbert; MCKENDRICK, Ewan. Transnational commercial law: texts cases and materials. Oxford: Oxford press, 2007.

ICAO. Convenção de Montreal 1999 sobre transporte internacional pelo ar. Disponível em: http://www.icao.int/secretariat/legal/List\%20of\%20Parties/Mt199_EN.pdf. Acesso em: 05.out.2017.

LANDO, Ole. A Proposal to Adopt Some International Principles of Contract Law. In: American Journal of Comparative Law, v. 53, p. 379-401. 2005. 
Principles of European Contract Law and Unidroit Principles: Similarities, Differences and Perspectives. Disponível em: www.cisg.law.pace.edu/cisg/biblio/lando6.html. Acesso em: 05.out.2017.

The Common Core of European Private Law and the Principles of European Contract Law. In: Hastings International and Comparative Law Review, n. 21, Summer, p. 809-823. 1998.

The Rules of European contract law. Disponível em: www.cisg.law.pace.edu/cisg/ biblio/lando2.html. Acesso em: 05.out.2017.

LORENZETTI, Ricardo. Sistema jurídico del Mercosur. In MARQUES, Cláudia Lima; ARAÚJO, Nadia. O novo Direito Internacional: estudos em homenagem a Erik Jayme. Rio de Janeiro: Renovar, p.645-675. 2005.

MCGREGOR, Harvey. Contract code: proyecto redactado por encargo de la Law Comission inglesa. Barcelona: Bosch, 1997.

MERCOSUL. Acordo de Buenos Aires sobre transporte internacional de cargas. Disponível em: http://www.mre.gov.py/tratados/publicweb/ ConsultaMercosur.aspx. Acesso em: 05.out.2017.

Protocolo de Ouro Preto. Disponível em: http://www.mercosur.int/msweb/SM/ Normas/PT/CMC_1994_OuroPreto.pdf. Acesso em: 05.out.2017.

Tratado de Assunção. Disponível em: http://www.mdic.gov.br/arquivos/ dwnl_1270491919.pdf. Acesso em: 05.out.2017.

MORAIS, Fabíola. Aproximação do Direito Contratual dos Estados-membros da União Européia. Rio de Janeiro: Renovar, 2007.

MORENO RODRÍGUEZ, José Antonio. Temas de contratación internacional, inversiones y arbitraje. Asunción: CEDEP, 2006.

OEA. Convenção Interamericana do México (1994): CIDIP V - sobre direito aplicável aos contratos internacionais. Disponível em: http://www.oas.org/ juridico/english/sigs/b-56.html. Acesso em: 05.out.2017.

OLIVEIRA, Renata Fialho de. Harmonização jurídica no Direito Internacional. São Paulo: Quartier Latin, 2008.

PARAGUAI. Constituição Nacional. Disponível em: http://www.oas.org/juridico/spanish/par_ res3.htm. Acesso em: 05.out.2017.

PEREIRA, Teresa Silva. Proposta de reflexão sobre um Código Civil europeu. In: Revista da Ordem dos Advogados Portugueses, v. 2, nov. 2004. Disponível em: www.oa.pt/Conteudos/ Artigos/detalhe_artigo.aspx?Idc $=31559$ \&idsc $=45841$ \&ida=47182. Acesso em: 05.out.2017. 
PONCIBÒ, Cristina. Some thoughts on the methodological approach to EC consumer Law Reform. In: Loyola Consumer Law Review, v. 21, n. 3, p.353-371. 2009

ROSSET, Arthur. UNIDROIT Principles and Harmonization of International Commercial Law: focus on Chapter Seven. Disponível em: www.unidroit.org/english/publications/review/ articles/1997-3-rosett-e.pdf. Acesso em: 05.out.2017.

SGECC. Study Group on a European Civil Code. Disponível em: www.sgecc.net. Acesso 05.out.2017.

THE COMMON CORE OF EUROPEAN PRIVATE LAW. Projeto sobre Contratos de objeto imoral na Europa. Disponível em: http://www.common-core.org/node/79. Acesso em: 05.out.2017.

Projeto sobre a interpretação dos contratos comerciais no Direito Privado Europeu. Questionário disponível em: http://www.common-core.org/sites/default/files/ uploaded/docs/QuestionnaireInterpretationOct2012.pdf. Acesso em: 05.out.2017.

Projetosobreremédioscontratuais.Questionáriodisponívelem:http://www.commoncore.org/sites/default/files/uploaded/docs/Questionnaire RemediesInContractLaw2011.pdf. Acesso 05.out.2017.

TRANSLEX. Translex Principles. Disponível em: www.trans-lex.org. Acesso 05.out.2017.

TWIGG-FLESNER, Christian. The europeanisation of contract Law. New York: RoutledgeCavendish, 2008.

UNCITRAL. A Convenção de 1978 sobre contrato de transporte internacional de mercadorias pelo mar. Disponível em: http://www.uncitral.org/uncitral/en/uncitral_texts/ transport_goods/Hamburg_status.html. Acesso em: 05.out.2017.

Convenção de Nova Iorque de 1958 sobre reconhecimento e execução de laudos arbitrais estrangeiros. Disponível em: http://www.uncitral.org/uncitral/en/uncitral_texts/ arbitration/NYConvention_status.html. Acesso em: 05.out.2017.

Convenção de Nova Iorque 2005 sobre utilização de comunicações eletrônicas em contratos internacionais. Disponível em http://www.uncitral.org/uncitral/en/uncitral_ texts/electronic_commerce/2005Convention_status.html. Acesso em: 1\%/10/2016.

Convenção de Nova Iorque 2008 para contrato de transporte internacional de mercadorias pelo mar. Disponível em: http://www.uncitral.org/uncitral/en/uncitral_texts/ transport_goods/rotterdam_status.html. Acesso em: 05.out.2017

. Convenção de Viena de 1980 sobre compra e venda internacional de mercadorias.

Disponível em: www.uncitral.org/uncitral/en/uncitral_texts/sale_goods/1980CISG.html. Acesso em: 05.out.2017.

Lei Modelo da UNCITRAL sobre assinaturas eletrônicas. Disponível em: http:// 
www.uncitral.org/uncitral/en/uncitral_texts/electronic__commerce/2001Model_status.html. Acesso em: 05.out.2017.

Lei Modelo da UNCITRAL sobre comércio eletrônico. Disponível em: http://www. uncitral.org/uncitral/en/uncitral_texts/electronic_commerce/ 1996Model_status.html. Acesso em: 05.out.2017.

UNIDROIT. Convenção da Cidade do Cabo de 2001 sobre garantias internacionais incidentes sobre equipamentos móveis. Disponível em: http://www.unidroit.org/status2001capetown. Acesso em: 05.out.2017

. Princípios UNIDROIT relativos aos contratos comerciais internacionais. Disponível em: http://www.unidroit.org/english/principles/ contracts/principles2010/translations/ blackletter2010-portuguese.pdf. Acesso em: 05.out.2017

VENEZUELA. Constituição da República Bolivariana da Venezuela. Disponível em: https:// www.oas.org/dil/esp/Constitucion_Venezuela.pdf. Acesso em: 05.out.2017.

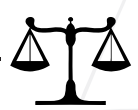

Recebido em: janeiro/2017

Aprovado em: novembro/2017 